\title{
Advantages and disadvantages of use of the internet for occupational pension schemes: An industry survey
}

Recerved. 30th July, 2004

\section{Kevin Wesbroom}

joined Hewitt Associates from Oxford University in 1975, with a first-class degree in mathematics and qualified as an actuary in $1978 \mathrm{He}$ has been with the organisation for his entire workıng life, enjoying a wide variety of roles including client consultıng and the review of pension plans and thought leadership in the pensions area. He has a particular interest in the ımpact of changing demographıc shifts

\begin{abstract}
This paper considers the development of the internet in relation to occupational pension schemes, the opportunities offered by the use of internet technologies, as well as the barriers to the growth of the use of the internet. A previous paper (Pensions Vol. 9, No. 4, pp. 348-364) set out the results of a survey of the use of the internet by UK company pension schemes in early 2003. The findings of that survey are incorporated here, together with direct quotations taken from survey responses, suitably anonymised.
\end{abstract}

Keywords: internet; pensions; communications; defined contribution (DC); defined benefit (DB); final salary; website; personalisation; self service

\section{Generic advantages of an internet presence}

The general advantages of an internet presence for any industry are usefully summarised as the 'Six C's' in Bocij et al, ${ }^{1}$ namely, cost reduction, capability, competitive advantage, communication improvement, control and customer service improvement. Table 1 below summarises their analysis and maps the themes onto the pensions space, with supporting comments from responses to the Pensions survey.

Kevin Wesbroom

Hewitt Associates

6 More London Place, London SE1 2DA, UK.

Tel +44(0)2079394346 Fax $+44(0) 2079394316$ e-mail kevin.wesbroom@ hewittbaconwoodrow com

\section{Pension managers' views}

Figure 1 below sets out the replies from pension managers to the question: 'What do you see as being the biggest advantages of internet-based communication and administration in the pensions area?' with multiple reples (up to three) permitted. The feature which comes through most strongly is the ability to improve the service offered to members - both in terms of the quality of information provided and its personal relevance, and also the opportunity to deliver it to members at a time and in a manner that suits their circumstances.

Perhaps rather too honestly, one reply said of the advantages of the internet; "in its current form none - but it just looks good!' (manufacturer). Keeping up with the Joneses is never a strong business case, but a very human one. 
Table 1: Advantages of an internet presence

\begin{tabular}{|c|c|}
\hline Feature & Potential applications to pensions \\
\hline Cost reduction & $\begin{array}{l}\text { The greatest savings in pensions come from the improved automation of routine } \\
\text { services, and the drive towards self service approaches. Self service can mean } \\
\text { either service by trustees and companies or by members themselves carrying out } \\
\text { routine transactions or modifications to their personal data via the web; '[lnternet] } \\
\text { will reduce need for repetitive admin tasks - such as change of address - to free } \\
\text { time for value added work' (technology developer). }\end{array}$ \\
\hline Capability & $\begin{array}{l}\text { The internet enables a broader range of interactions with pension scheme members, } \\
\text { including opportunities to contact, communicate and transact outside of normal } \\
\text { office hours; 'A dedicated website provides an excellent communication tool for } \\
\text { pensions, since information can be provided and obtained quickly and conveniently } \\
\text { in a way and time that suits the member' (retailer). This can also mean, for } \\
\text { example, that a multi-national employer can offer consistency of service response to } \\
\text { its global workforce. }\end{array}$ \\
\hline $\begin{array}{l}\text { Competitive } \\
\text { advantage }\end{array}$ & $\begin{array}{l}\text { Rarely a consideration in company pension schemes, but one would hope that a } \\
\text { compelling internet presence would support an employer's attempts at developing } \\
\text { their own 'employment brand'. The most dramatic illustration of this feature has } \\
\text { been the decline in the number of players in the commercial Stakeholder market } \\
\text { where the stakes were high (in the form of substantial investment to automate } \\
\text { processes by several orders of magnitude) and only those prepared to commit } \\
\text { significantly will have any hope of recouping their investment and thereby gain } \\
\text { competitive advantage. }\end{array}$ \\
\hline $\begin{array}{l}\text { Communication } \\
\text { improvement }\end{array}$ & $\begin{array}{l}\text { The ability to enhance the quality and quantity of communication material offered to } \\
\text { members (and to trustees) was discussed significantly in the earlier article, and is } \\
\text { considered further below. }\end{array}$ \\
\hline Control & $\begin{array}{l}\text { In the sense of generic advantages of the internet, this refers to increased control } \\
\text { by consumers, for example in relation to access to their personal information such } \\
\text { as banking data. Control of data access appears far more often on the negative } \\
\text { side of comments about the internet for pensions at this stage; 'Ensuring security of } \\
\text { data will deter investment in the administrative aspects [of the Internet]' (retailer). }\end{array}$ \\
\hline $\begin{array}{l}\text { Customer service } \\
\text { improvement }\end{array}$ & $\begin{array}{l}\text { There is little doubt that the internet extends the opportunities for members to learn } \\
\text { about pensions, and transact their pensions business, outside of the workplace, } \\
\text { assuming they can be persuaded to take the time to find out; 'With the correct } \\
\text { demographics of members and employees, Internet based communication would be } \\
\text { a fantastic step forward, particularly as regards accessibility' (aerospace engineer). }\end{array}$ \\
\hline
\end{tabular}

\section{Service to members}

It is clear that pension managers have a strong desire to increase and improve the range of interactions they have with their members, in an effort to improve the understanding of pensions, and they see the internet as one of the key tools they can use in this mission. The availability of the internet outside of traditional office hours and the working day of the pension manager is a key advantage; the Martinı principle (anytime, anyplace, anywhere) of web access can move from being a fanciful notion to an everyday part of life. We can sometimes forget just how rapidly technologies can become pervasive - think of mobile phones, or home banking or internet shopping via
Amazon and the likes. Just seven years ago. only 10 per cent of the adult population used the internet -57 per cent do so now. Pensions may take longer to join the list of information routinely accessed via the web, but as expectations change, then occupational schemes will need to invest to stay up with the technology demands, or outsource or buy in these services.

\section{Communication and education}

One of the classic themes of the internet is that this medium does not force one to compromise between what Evans and Wurster $^{2}$ call 'richness and reach'.

Richness of information refers to the 


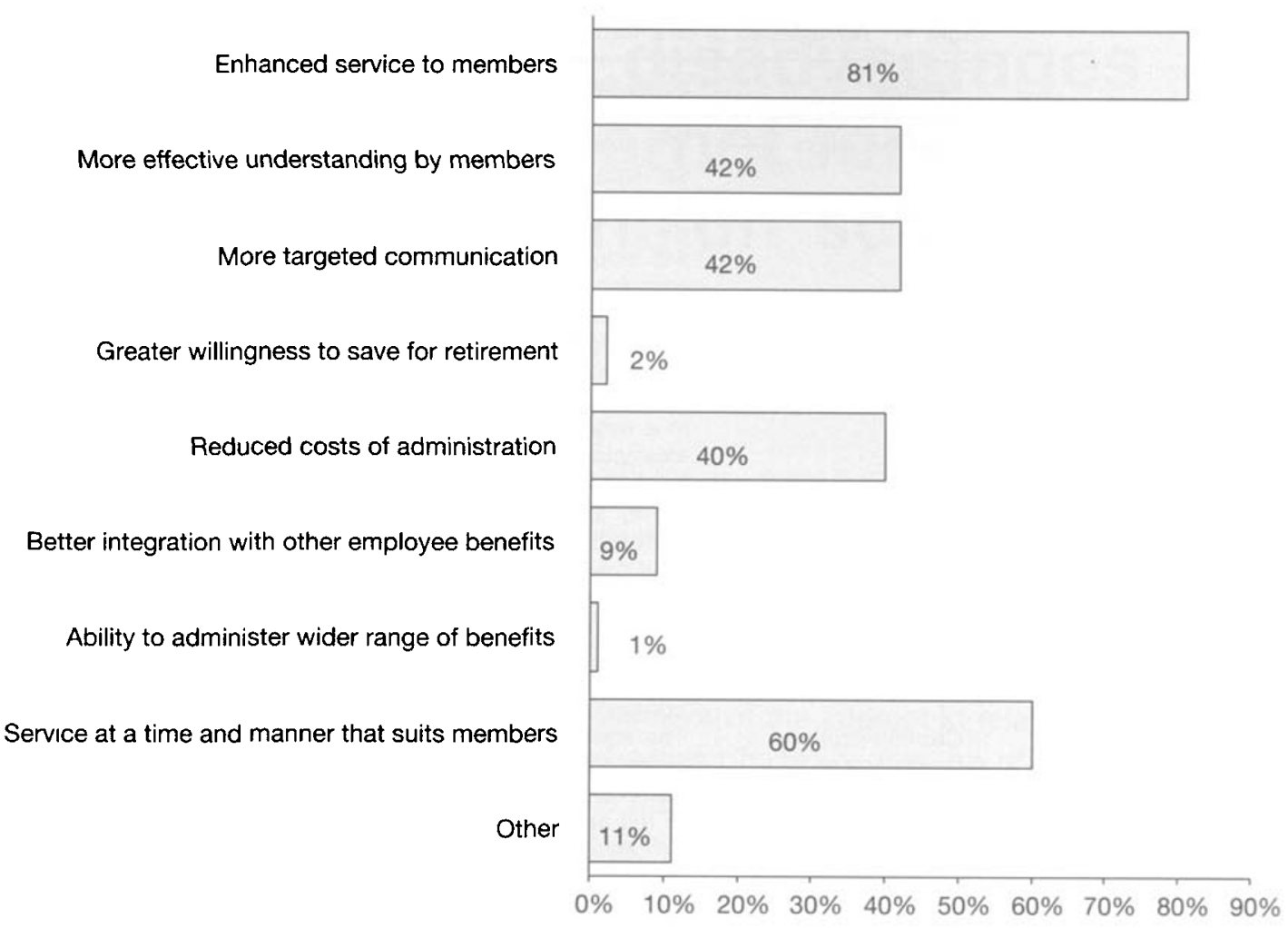

Source: All completed responses to Pensions survey

Figure 1: Biggest advantages of the internet

quality, relevance, and personalisation of that information, whereas reach refers to the size of the potential target audience we can connect to. Traditional communication methods either select quality - via personal conversations or presentations - or quantity, in the form of awareness campaigns, posters, etc. The ability of the internet to offer 'mass customisation' - in other words to reach a large group of people, but deliver information that is specific to their circumstances - enables us not to compromise on richness or reach. The success of the different communication mechanisms will obviously vary from scheme to scheme depending on the membership profile and internet access for all categories of members, but the principles are illustrated in Figure 2 below.
Communication and pensions have always gone hand in hand - because of resistance to the basic concept. The very product itself is intangible, and deferred a long way into the future. People do not want to think about pensions because as one communicator said 'it's to do with getting old and having less money'. And we start from a relatively poor knowledge base; as the Department for Work and Pensions (DWP) ${ }^{3}$ state:

'evidence suggests that most people have a limited understanding and awareness of pensions and the pension system'.

Providing information about pensions personal projections of emerging levels of benefit from a DC plan delivered via the web - may generate a sense of urgency and immediacy that prompts people to take action; procrastination is one of the great enemies of retirement savings. 


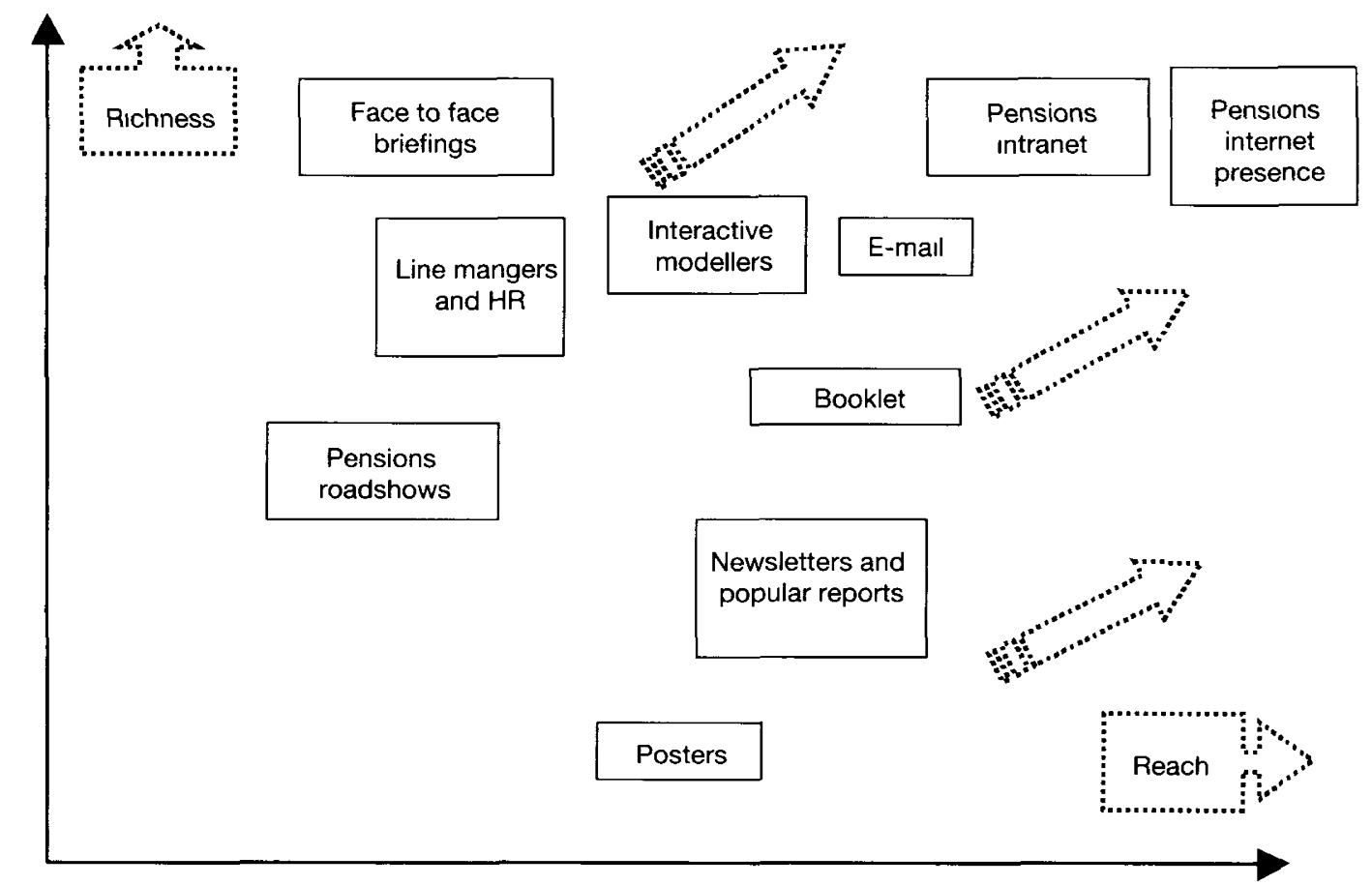

Source: Based on Evans and Wurster ${ }^{2}$

Figure 2: Richness and reach in pension communications

Figure 2 above considers communications with the members of the plan, typically from the employer or the trustees. There are many parties involved in pensions all of whom may have their own communication agendas. The employer wants to communicate the value of the benefit he is providing, to make sure members appreciate it fully, and that they are making the best choices amongst those available. The provider - eg insurer - wants to maximise sales. The government wants to encourage people to save more to move them away from state provision. Each of these aspects of communication can be facilitated by internet technologies.

\section{Government communication}

The DWP Green Paper ${ }^{3}$ is full of ideas and initiatives around communications, with a view to getting people to pay more towards their retirement; 'if informed and empowered, many would choose to save more than they do'. They propose a significant emphasis on technological solutions including personalised interventions to maximise effectiveness, a range of communication channels (written material, websites, call centre support, and even interactive digital television) and an interactive retirement planner. The latter is an ambitious project that will offer projections of combined benefits from the state and - in its widest development - all private sector pensions. It is a very bold visionary project, only possible via the internet and standard information exchanges, but the key building blocks are in place.

\section{Manager to manager}

Chat rooms have been a feature of internet communities in most areas of 
endeavour, and so it should not be a surprise that a chat room for managers has emerged in the pension community.

The online community www.pensionwebcommunity.com was launched by a specialist pensions communication firm, with the intention of offering an online location where pension managers could meet together to discuss issues that concern them, without payment and overt selling. Whether the service remains free, or becomes a subscription service longer term, is an interesting question - indeed the website www.endoffree.com exists simply to catalogue the trend away from the days when the web stood for free information!

\section{Pension regulators - the FSA}

The Financial Services Authority (FSA) saw from early days the potential uses of the internet and the twin themes of education/information and

efficiency/administration. The Chairman of their e-commerce workstrand said: 'We are looking, for example, to tap the potential the internet offers in the area of consumer education and how to make good use of the new technologies to improve the efficiency and economy of our regulation'. The FSA were amongst the early adopters of technology to provide education and information for consumers, including pension consumers. They launched comparative tables on the web - with pensions featuring prominently - as one of the ways of applying new technology to help make an informed, online choice, although with the expectation that the actual transaction will be effected using face to face (F2F) methods. The FSA and the Association of British Insurers (ABI) also launched a very useful - if not very appealing - pension projection model that can be found at www.pensioncalculator.org.uk.

\section{Pension regulators - OPRA}

As the principal pensions regulator (at least until it is replaced by the new regulator under the Pensions Act 2004) OPRA sponsors a significant website for its own services, as well as offering guidance for pension professionals on the use of the internet. As yet they have not launched what would be, one of the most valuable features for a website an online tracing service to help individuals locate the various preces of deferred, frozen or personal pensions they have accumulated over their career - a 'Pensions Reunited' website in effect! Whether this emerges as part of the DWP modeller referred to above remains to be seen.

\section{Communication - effectiveness}

It is worthwhile asking whether the efforts for communicating with members, vid the internet or otherwise, are actually paying off, in terms of greater understanding or increased levels of savings. To date the evidence appears to be that there is still a long way to go. In a survey of the DC and additional voluntary contribution (AVC) marketplace, Hewitt Bacon \& Woodrow ${ }^{5}$ considered the methods used for communicating with members, illustrated in Figure 3 below.

It is clear that a vast array of communication techniques are used, with internet and intranet methods showing significantly increased rates compared, for example, with the figures in surveys just three years earlier. But one of the most telling outcomes of this survey came from asking pension managers how much of the basic messages around DC had been taken on board by members. A 




Source: Hewitt Bacon \& Woodrow DC/AVC survey $2004^{5}$

Figure 3: DC communication methods

frightening 97 per cent said they felt that DC members did not have a clear understanding of the amount needed to save for their retirement. Even more alarmingly, 78 per cent said that DC members did not understand they were carrying the risks in their plans, rather than the employer. It is clear that we need to continue to press home some very basic messages about saving for retirement - risks, how much to save and where to invest. Interactive modelling programs delivered via the web can play a key role in this, and can become increasingly sophisticated to help make messages more effective.

Segmentation techniques borrowed from marketing disciplines can help guide individuals who are accessing a website to the information that is most relevant to them, and most likely to generate the desired response.

\section{Administration}

It is clear from Figure 1 that pension managers see the biggest opportunities from the internet as enhanced communication and interaction with members. Reducing the cost of administration only ranked fifth on their list of priorities. It is true that at present the costs of administration of final salary schemes are dwarfed by the general financial difficulties these schemes face; over time however, the desire for greater efficiencies, particularly among closed schemes, will predominate. The facilities offered to members by commercial providers in many cases are ahead of those in the corporate sector, where there has been arguably less of an imperative to cut costs and automate. More recent evidence suggest that the combination of the move to DC and the appalling funding levels of final salary 


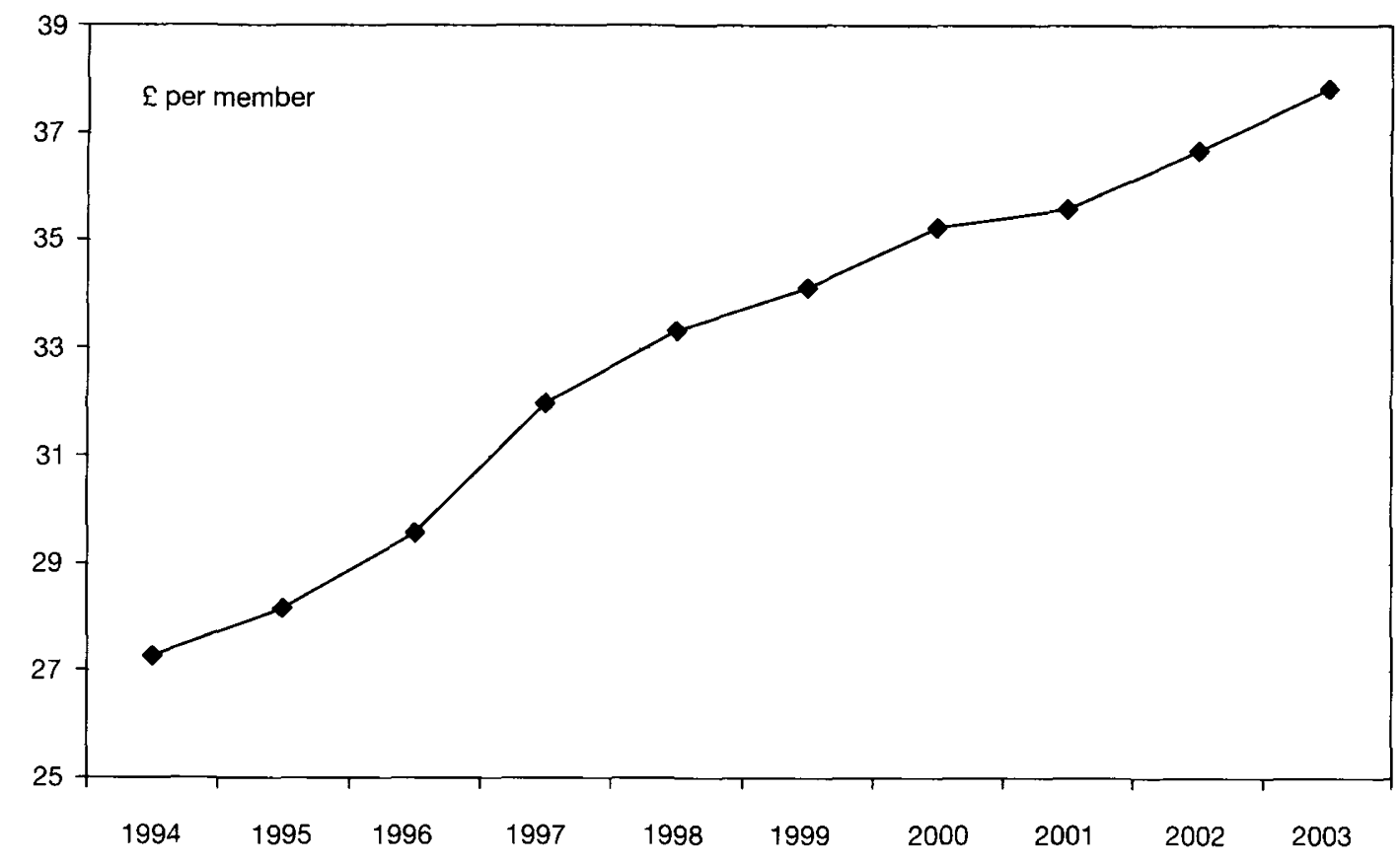

Source: Capita Hartshead 2003 survey $^{6}$

Figure 4: Cost of in-house administration

schemes (and consequential increases in costs) has led to more attention on cost-driven outsourcing in the self administered arena. It is in the commercial interests of the outsourcers to apply the same logic as insurers to develop self service approaches, and highly automated solutions. Otherwise costs for in-house administration seem to continue to rise inexorably, with little signs of payback from any investment in technology and automation, as Figure 4 shows.

There is a marked contrast between the approaches generally taken to date amongst in-house self administered final salary schemes and the commercial DC marketplace. For anybody working in the pensions industry, the conventional wisdom for many years was that the insurance sector had a reputation for poor quality systems and low standards for pension administration. Stakeholder changed all that; the imposition of the
1 per cent cap on charges led to a massive investment in web-based systems and re-engineering of business processes to be able to make money in this environment. This investment in automation means that the insured (and outsourced) providers have the potential to lead the in-house self-administered sector. Commercial providers do not have the luxury of heavy levels of manual intervention to compensate for poor processes and must drive for ever more automated approaches, such as straight-through processing. IT commentators Forrester Research ${ }^{7}$ are convinced that providers must drive straight-through processing throughout the entire value chain, eliminating paper based processes and other inefficiencies like re-keying of data between distributors and manufacturers.

Certainly the attraction of using internet-based administration systems has been recognised in the broader financial 
Table 2: Comparative costs of administration

\begin{tabular}{lc}
\hline Agent/IFA & $\$ 19$ \\
Call centre & $\$ 8$ \\
Internet & $\$ 0.45$ \\
\hline
\end{tabular}

Source: Cornall et al: Annual cost of administration of Personal Lines Insurance policy

services sector, since the almost legendary analysis produced by consultants Booz, Allen \& Hamilton on comparative costs of different banking channels. A paper called e-actuaries ${ }^{8}$ looks at the cost of administration of US personal line insurance (our closest proxy for pensions) summarised in Table 2 above. As ever there appear to be massive potential savings from web systems. Even if pensions products and processes can be simplified for delivery via the web, however, capturing the gains offered by new internet systems may prove more difficult - if not impossible - where alternative distribution channels are also offered. Many commercial pension providers in the UK have found this to their cost, as systems have proliferated with new 'clean' internet systems having to integrate with a variety of legacy systems. To date we have seen no significant new entrants to the pensions marketplace who are operating on a 'pure play' internet-only basis, comparable to the likes of egg in the personal finance space. Perhaps the changes offered by the Inland Revenue simplification of pensions taxation ${ }^{9}$ will finally tempt some new players in the pensions arena?

Even with the news of an increase in the price cap on Stakeholder products from 1 per cent to 1.5 per cent (for the first ten years), the prognosis for commercial pension providers in the UK is not good. Despite their substantial investment in technology and internet solutions, it is not obvious that there will be room for all of them to make money. Brian Hague, a third-party evaluator ${ }^{10}$ calls their investment an 'act of faith' in many cases, and sees them as grasping at internet technologies as offering some sort of hope of ever being able to make money under stakeholders' limited charges. When asked how long it would be before these providers saw a pay back on the significant amounts invested in new systems he said, 'realistically, not many of them are going to make money ever'. The raising of the cap on stakeholder products to 1.5 per cent may give hope that some return is seen this side of infinity! But the drive to the web may be the saviour of those who choose to play in this market. As Buchan " puts it "Hitherto in the pensions industry, the Internet has been seen as a useful gimmick at best, but the new [stakeholder] regime has accelerated Internet based administration facilities to the status of being a pre-requisite'.

\section{Barriers to growth}

Pension managers gave some fairly consistent messages about why exponential internet growth is unlikely. Responses to the question 'What do you see as the biggest deterrents to the growth of the use of the Internet in pensions?' are summarised in Figure 5. Once again multiple responses were permitted.

The 40 per cent 'Other' responses covered a number of areas including trust, security concerns, legal issues, accessibility by staff, comprehension by staff and cost.

\section{B2C or F2F?}

The overwhelming issue that the internet cannot overcome in the pensions area is the need for face to face explanations. Many managers chose to make comments to this effect; 'most people prefer to speak to some one directly' (utility). 'People want to have things 


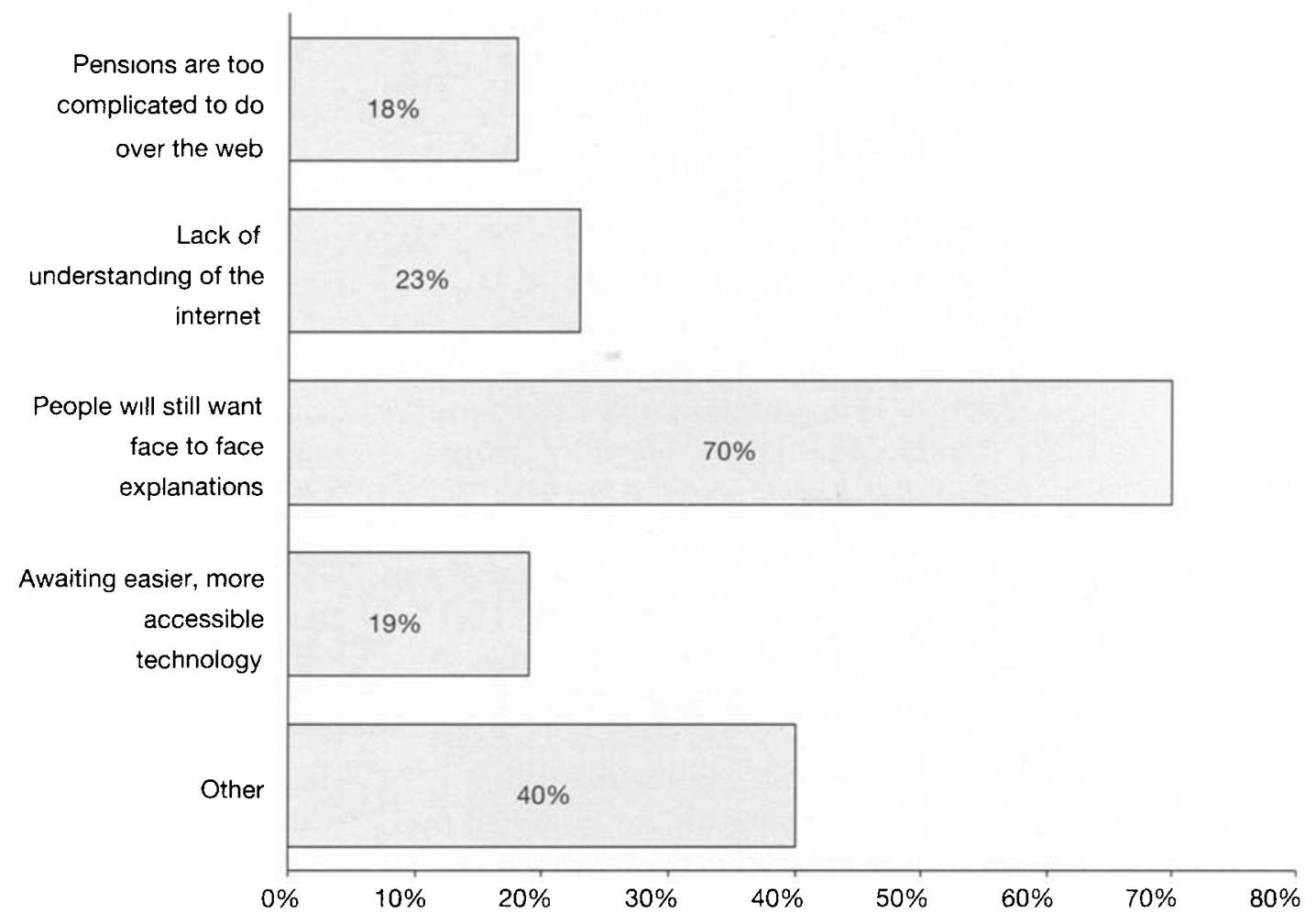

Source: All completed responses to the Pensions survey (101)

Figure 5: Biggest deterrents to the growth of the internet

explained and talk to a person' (retailer). 'Members still prefer to talk to a real person about their benefits' (leisure).

'The majority of membership will always prefer face to face communication'

(bank). The percentage citing this as the key deterrent was noticeably lower amongst DC schemes - perhaps a case that they have seen what can be done, or of a greater neccessity? Many respondents to the Pensions survey felt that internet communication was a poor second to the 'real thing' ie face to face communication. Perhaps they believe that the message is less important than the medium. In their book 'e-pensions' 12 the authors cite that in personal communication, the significant factors in delivering a message are accounted for by 55 per cent visual features (ie body language) 38 per cent aural issues (ie the way we say things) and only 7 per cent for the message itself. They conclude that a pensions website has to compensate for the 93 per cent of communication that arises from the lack of human interaction. Apart from the practicalities or impossibilities of face to face communication for a major employer with many thousands of employees on multiple sites, this also misses a potentially important point. Some people might prefer the internet as their means of learning. Well-constructed material 'allows people to take in information at their own pace' (pharmaceuticals) and can offer the ability to learn in a style that suits people, who may be embarrassed by asking stupid questions in open forum. Fowler ${ }^{13}$ encapsulates this excellently: 'the notion that a remote relationship can actually be 
Table 3: Product value proposition for onlıne adoption

\begin{tabular}{lllll}
\hline Drivers & Current account & Motor insurance & Broking & Pensions \\
\hline Cost savings & $\checkmark$ & $\checkmark \checkmark$ & $\checkmark \checkmark \checkmark \checkmark$ & $\checkmark \checkmark$ \\
Convenience & $\checkmark \checkmark$ & $\checkmark \checkmark$ & $\checkmark \checkmark \checkmark$ & $\checkmark$ \\
Lack of complexity & $\checkmark \checkmark \checkmark \checkmark$ & $\checkmark \checkmark \checkmark \checkmark$ & $\checkmark \checkmark \checkmark$ & $\checkmark \checkmark$ \\
Enhanced control & $\checkmark \checkmark \checkmark$ & $\checkmark \checkmark$ & $\checkmark \checkmark \checkmark \checkmark$ & $\checkmark \checkmark \checkmark$ \\
Choice & $\checkmark$ & $\checkmark \checkmark \checkmark$ & $\checkmark \checkmark \checkmark$ & Unlikely to be \\
Conclusion & Value proposition & Likely to have good & Killer online & large online \\
& needs to be & early online adoption & application & unless made \\
& enhanced & & & simpler \\
\hline
\end{tabular}

intimate is not the only irony implicit in the potential of the Web'. Of course the leading thinkers do not see it as a choice between face to face or internet communication: 'It [the internet] won't ever replace face to face, but I would say why not have face to face communications on the internet?' (communication specialist). And other survey responses see internet approaches as just one of an array of measures that companies will use to get their pension messages across to members: 'the internet is only a small part of good communication that will always remain multi-layered' (retailer).

\section{Complexity}

Even if the reality is that commercial pension products are now simpler, there is no doubt that the fear amongst potential purchasers - or members of company scheme - is that they are still complicated, and they will not enjoy the experience. In relation to commercial sales, JP Morgan ${ }^{1+}$ see the adoption of online financial services generally as an equation of the form:

$$
\begin{aligned}
\text { Adoption }= & \text { Function }(\text { Cost } / \\
& \text { convenience, complexity, } \\
& \text { choice, control) }
\end{aligned}
$$

They see pensions as scoring rather poorly on this basis, compared with other financial services products:
Complexity - or more likely fear of complexity - is still a major deterrent to transacting pensions business via the web. Like other complex financial products, however, buyers are increasingly comfortable at using the internet as a source of information and advice, but then using a different approach - typically face to face - for the actual transaction. Two-thirds of US mortgage buyers research online, but only a handful will transact. This approach seems to be a recurring theme amongst pension managers who see the internet as a helpful source of information for members but not a substitute for the real thing; 'The Internet is a useful tool but, in my view, cannot replace face to face communication' (motor manufacturer).

\section{Access}

Several replies commented that their members lacked access to the internet either at work or at home. Perhaps not surprisingly, this was an issue for those with a large proportion of manual employees; 'we must not be drawn into the illusion that most people have access to the web: in our industry many of our staff are at best semi-skilled eg warehouse operatives and there is no access at work and only slowly growing access at home (manufacturer). Several pointed out the disparity between different sectors, 'if I were a bank I would probably use the 
internet for communication but a high percentage of my members are manual employees with no access at work to a computer' (manufacturer). Some felt that their employer was not being creative enough to facilitate web access, 'there should be willingness from employers to allow employees to access the internet for specified purposes (eg pensions) during the working day, and to give employees the facilities to do so.' (retailer). It is perhaps worth reminding ourselves, however, that over 29 million people now have access to the internet in the UK, and this figure could rise even further if new access methods such as interactive digital television become more widespread.

There are well rehearsed arguments (eg Caffey and Strip ${ }^{15}$ ) about whether digital television will be used to carry out financial transactions - for example, during the advertisements on Big Brother Ten? The general view seems to be that 'lean back' technologies in the living room will not replace 'sit forward' technologies such as a PC in the study or workplace. The pervasiveness of mobile phones perhaps offers another technological route to disseminate information? Why not text to the user - on a quarterly basis say - a short text message 'Your DC fund is now worth $\mathcal{L}_{\mathrm{x}}$ - if you would like more information go to this website'. Or would personal pension information like this just be rejected as another form of spam?

\section{Data security and trust}

Trust appears regularly as one of the features limiting the growth of e-commerce and has a number of aspects - eg protection of personal data. Given the scandals that regularly appear in the Sunday papers about unauthorised disclosures of personal data, many have an overstated fear that their personal details will inadvertently be released to others, or that their personal information will be packaged and traded as commercially valuable data. A book called 'The Cluetrain Manifesto"16 offers one of the most prosaic encapsulations of this general fear, 'From time to time we offer to share our list of subscribers with door-to-door aromatherapy salesmen and ritual axe murderers. If you would prefer that your data is not used in this way, please click the box'. Most employees would have confidence that their employer would not abuse their personal data for commercial gain, but the fear of security breaches still influences opinion. 'I don't think people are comfortable enough with the internet to transact personal business' (manufacturer). 'Ensuring security of data may deter investment in the administration aspects' (retailer).

\section{Legal issues}

One of the issues which seems to be a regular cause of concern for trustees is whether they can satisfy their legal requirements to provide information to members via material on a website. The majority still provide paper copies just in case, although there are already some examples of forward thinking schemes, in the IT sector, who provide all information - booklets, forms, benefit statements - only in electronic format. The general body of opinion supports the view that internet approaches satisfy UK requirements. In 'e-pensions', ${ }^{12}$ the authors conduct a detailed analysis of the disclosure of information regulations, with the regulations' archaic references to information being 'furnished' to members, and sometimes 'in writing'. Their conclusion is that 'electronic means (such as making information available on websites or intranet sites, or 
sending information by e-mail) generally can be used to satisfy the statutory obligations.'

\section{Comprehension and data quality}

Pension managers have concerns that members will not understand what they find on a website - in part, this explains their preference for face to face methods, so that they can ensure comprehension. Many have concerns about liability on themselves, or 'the serious possibility that members would be taking some action (or even some inaction) as a result of inappropriate quotations obtained from the intranet site'. ${ }^{11}$ This is a real problem - which can only partly be resolved by good design. Given the responsibility of trustees to their members, it is perhaps not surprising that they try to protect their members from the consequences of incorrect important strategic decisions as a result of poorly understood online quotations. Several pension managers feel they will be in the firing line to clear up any ensuing mess; ' $I$ think there is an assumption that administration will be made easier if members use the Internet - I don't believe it will reduce workloads' (financial services). Of course, misleading conclusions can be drawn as a result of misleading or incorrect data. Poor quality data would seem to be almost an intrinsic feature of the pension landscape - but one which cannot survive a transition to internet-based solutions. You cannot present poor or incomplete data to members on a beautiful new website - it simply undermines any credibility in the process or the outcome. The commercial software and systems providers in the pensions trade press regularly bemoan the time and cost involved in getting data sufficiently clean to be offered up via a website. Given the number of acquisitions, mergers, special benefit scales and tranches of benefits in a modern final salary scheme, poor quality data may not be surprising but it still needs to be resolved. A decision to move to the web may be just the spur needed to resolve those historic data issues once and for all.

\section{Cost}

A surprisingly large number of managers argued that they could not get the resources or backing to launch an internet site. Looked at from a strict cost/benefit standpoint this is probably not surprising. One response pointed out that for smaller schemes (say less than 10,000 members) 'I don't see there being sufficient savings in admin/staff costs to justify the cost of web enablement' (financial services). One manager of a final salary scheme admitted that his perspective might be different if he operated a DC plan, but with his current set up 'I am sceptical that the required investment in websites will ever be available or justified' (construction). Of course, timing is everything, and the current crisis of pension funding with massive deficits is not the time perhaps to be raising what many would argue is a non-essential investment like a website. Equally, cost is not the only constraint on available resources to give the opportunity to build an intranet or internet site. There is far too much on a typical trustee's agenda nowadays, with deficits, benefit changes, increased contributions and retrospective legislation changes for example, to squeeze in something as frivolous as a website. 'The barner to further development is trustee time' (technology).

\section{The internet as a threat?}

Finally, one of the barriers to internet growth is undoubtedly the pension 
managers themselves, in their role as gatekeepers. This can be as 'simple' as their personal discomfort with technology. One reply said that his company had no website, 'I am a bit of a dinosaur when it comes to technology and have to be forced to apply it only when necessary' (construction). This discomfort could also be a concern about the eventual implications of automation and web technology on their own working environment and work prospects. One pensions article from an outsourcer predicted that we could see unmanned pensions offices within the next 10 to 20 years, and one other response to the Pensions survey said somewhat ominously "websites will totally replace conventional pensions departments in the fullness of time' (manufacturer). Managers may not be too keen to hasten their own demise!

\section{Communication or administration?}

In response to the question posed in the survey 'Will the internet have a bigger impact on the administration of pensions or their communication?' pension managers voted 29 per cent in favour of administration and 71 per cent in favour of communication. 'Communication will have the biggest impact initially, but longer-term it will be administration.' (retailer). It is clear that the internet has a significant opportunity to play a leading role, both in improving the understanding of pensions and in improving the efficiency of delivering pensions. In terms of timing, 'initially communication with static websites; progressively it becomes administration' (IT supplier). There was no marked difference between final salary and DC schemes, but some strong sector variations. Financial services companies were the strongest advocates of communication with 89 per cent in favour; manufacturers were the most optimistic about the administrative aspects, with 53 per cent supporting this rather than communication.

In part, the slow pace of development may be no more than natural caution amongst the pension community, but two key deterrents emerge, in the form of poor quality data and the sheer complexity of pensions, which many pension managers see as leading to a continued need for face to face explanations. The author's view is that the educational aspects will predominate for the next five years, but as increasing focus is put on the costs of administration of closed final salary schemes, web-based self-service will become a necessity.

\section{Ahead of its time?}

It may be that we simply have to be more patient and wait for internet applications to be more prevalent in the pensions space. Perhaps we can look to the USA - regularly cited as the future in these areas.

One of the features of the development of the commercial DC market in the USA, has been the growth of services offered to plan sponsors. Technology has a major role to play in terms of delivering these enhanced communication, education, access and administration functions in the most cost effective fashion. Figure 6 shows that the features offered to participants have exploded. The proliferation is referred to as an 'arms race' and as in many other arms races, the cost of staying in the game can become crippling, and eventually lead to the downfall of some of the players. The new services are increasingly web onented - starting with access to information (via the telephone, the web and now personal 


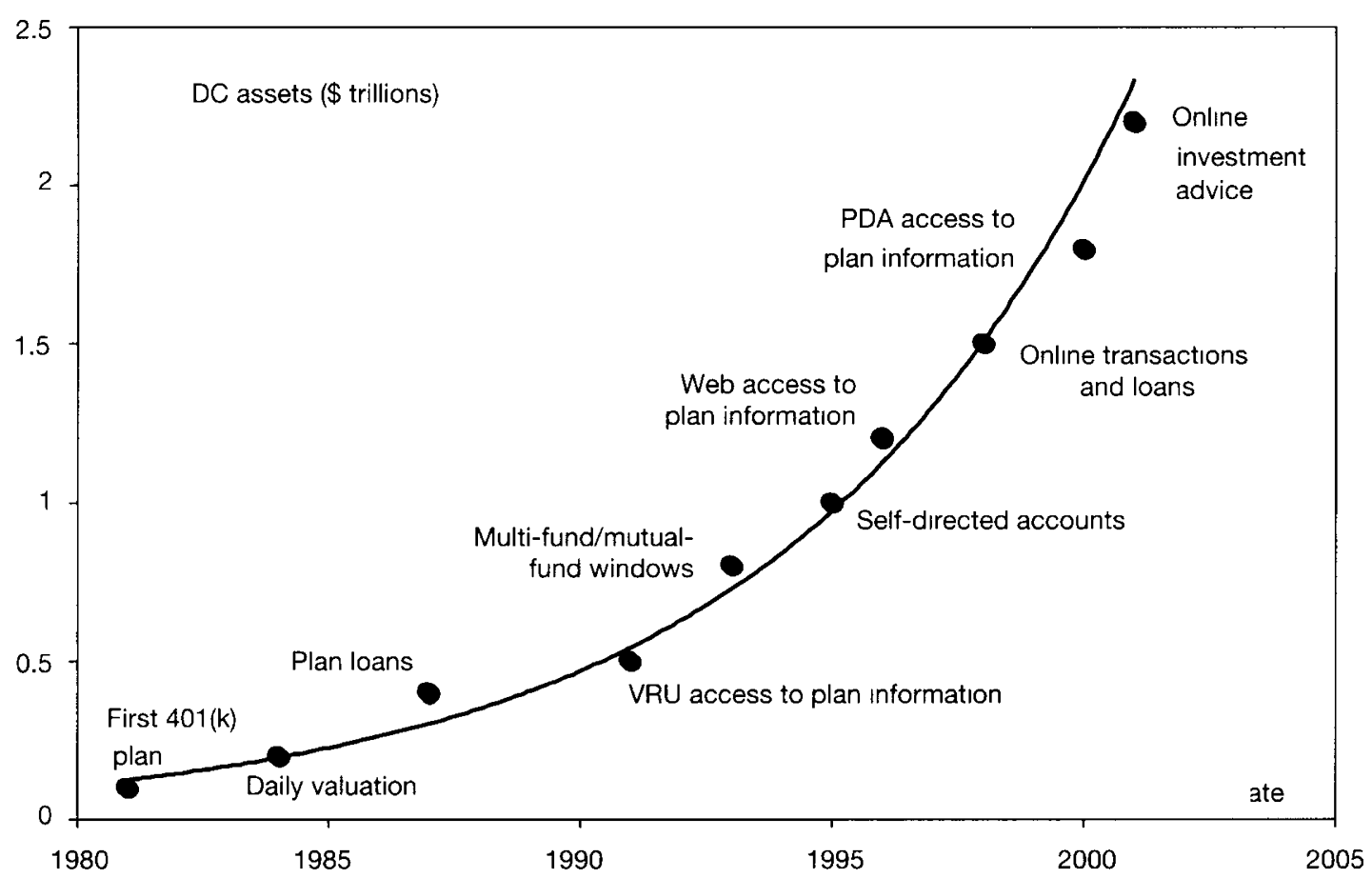

Source: Retirement Services Roundtable Data Coliection Exercise 2002

Figure 6: The 'arms race' in US DC plans

digital assistants (PDAs), but interestingly not mobile phones, or cell phones as our US colleagues call them) but soon moving into transactional capabilities and remote delivery of advice on investments.

More to the point, it is not obvious that all of these enhancements are actually used by participants or valued by them. It is argued that many of these enhancements are demanded by consultants as a condition before providers will be considered for recommendation to the end clients, 'providers have turned service enhancements into a mandatory sales ante'. ${ }^{17}$ Figure 7 contrasts the availability of features with their usage by plan participants. To provide these services costs a great deal, but they do little to satisfy an unmet demand or increase participant satisfaction. Brian Hague agrees that a similar theme emerges in the UK, in that many 'hygiene' features insisted on by consultants for beauty parade purposes are not fully used by members: "you could accuse the consultants of making too much of an issue of these new features'. ${ }^{11}$ Other commentators suggest that the market's perception of suppliers who are seen as innovative is not proportionate to the benefits. In other words you have to be seen as forward looking, even if the key requirements are somewhat static: 'the feel-good factor for innovation is greater than the resultant functionality warrants'. One pension manager summarised this disparity between features and usage as, 'few of our members are screaming for internet access' (manufacturing).

To which the author would add a final coda - 'not yet'. The internet is the way of the future for both corporate and commercial pensions alike, and will have a key part to play in getting 


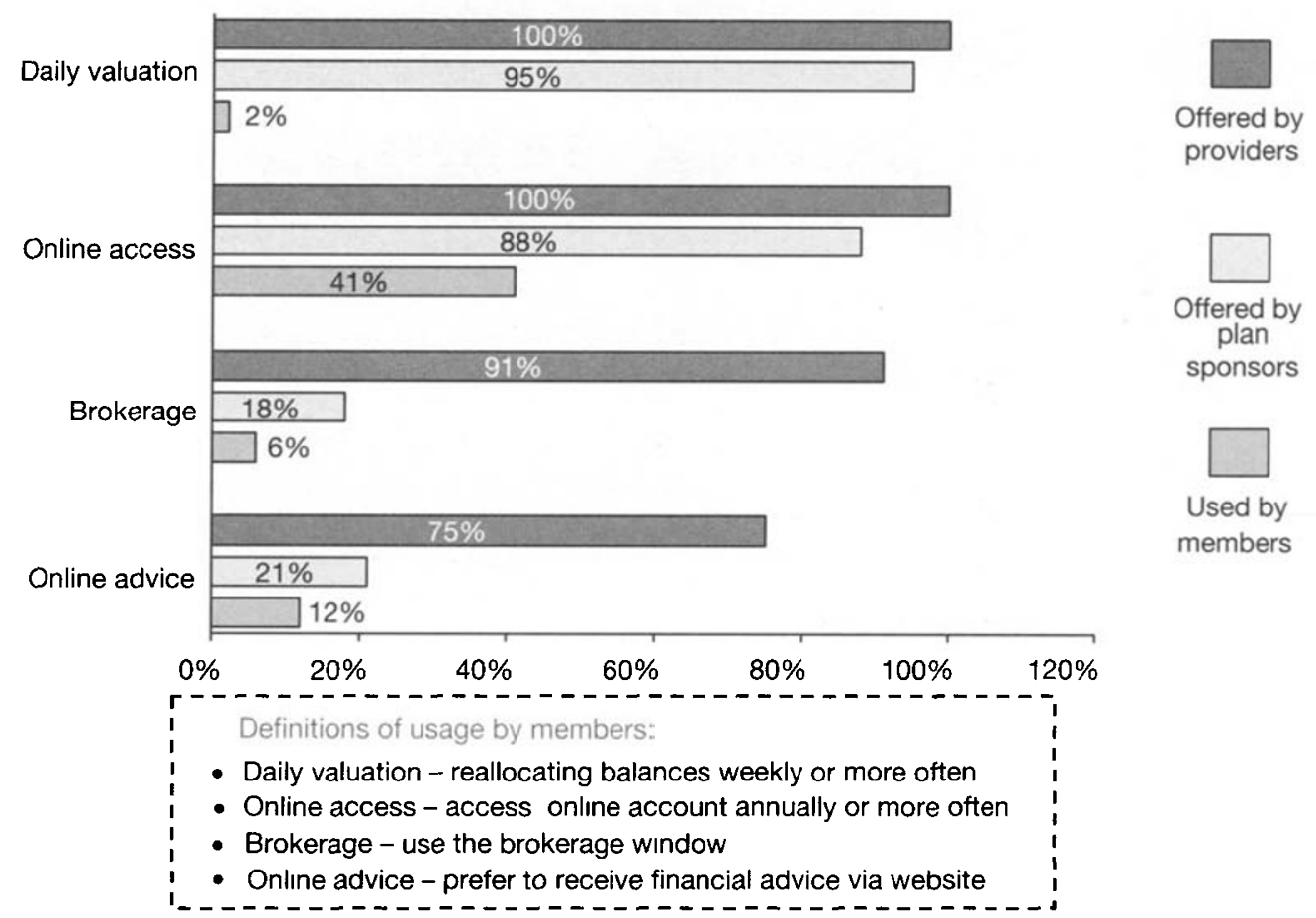

Source: Retirement Services Roundtable 2002 and Hewitt Associates

Figure 7: Adoption and usage of DC plan services

members to accept their role in planning for their own retirement.

\section{References}

1 Bocij, P., Chaffey, D, Greasley, A. and Hickıe, S (1999) 'Business information systems. Technology development and management', FT Management, London.

2 Evans, P and Wurster, T (2000) 'Blown to Bits, How' the New Economes of Information Transform Strategy', Harvard Business School Press, Boston MA

3 Department for Work and Pensions (20)2) 'Simplicity, secunty and choice, Working and saving for retirement'. HMSO Cmd 5677, December 2002

4 Robinson, P. (2001) 'E-commerce heralds a new era for financial services', Financial Adviser Technology Extra, 1st edition, Financial Times Business, 31st May, 2001.

5 Hewitt Bacon \& Woodrow (2004) 'Annual Survey of DC and AVC Marketplace', London, May 2004

6 Capita Hartshead (2003) 'The 10th annual pensions administration survey', Capital Business Services Ltd, May

7 Ensor, B (2001) 'Unwrapping UK pensions', Forrester Research, London, April 2001

8 Cornall, M. Jolif, N., Anmashashun, $A$ and Athwal, G. $(2000)$ 'E-Actuanes', The Staple Inn Actuaral Society; June 2000
9 Inland Revenue, Simplifying the Taxation of Pensions, December $20(1) 2$ and $2(0) 3$ and Finance Bill 2004

10 Hague. B interviewed in Wesbroom, K (2(k).3) e-Pensions, Dissertation for Masters Degree in e-commerce, University of Kent

11 Buchan, I (20)1) 'Internet, the only way ahead for pensions? Joumal of Pensions Management, Vol 6, No. 4 , pp 305-310

12 Barker, F, Blackwell, J, Hall, P, James, $T$ and Ryland G. (20112) 'e-Pensions'. Tolley Lexis-Nexus, UK.

13 Fowler, G (2002) 'No monkey business - what investors need to know and why', Financial Times, Prentice Hall, Pearıon Education Limited, Harlow; UK

14 van Steen1s, H (2000) 'Online finance Europe Invasion of the customer snatchers', JP Morgan Secunties Ltd, June, London.

15 Coffey, S. and Stripp, M. (1997) 'The interactions between computer and television usage', Journal of Advertising Research, Vol 37, No 2, pp 61-67

16 Locke, C, Levine, R., Searls, D and Wemberger, D (1999) 'The Cluetran Manifesto The End of Business as Usual', Perseus Publishing, Reading. MA

17 Retirement Services Roundtable (2(1)2) Follow the money Strategies for realigning the economics of the defined contribution busmess', Corporate Executive Board 